\title{
Hereditary continuous muscle fiber activity
}

INSERM

\section{Source}

INSERM. (1999). Orphanet: an online rare disease and orphan drug data base. Hereditary continuous muscle fiber activity. ORPHA:972

Hereditary continuous muscle fiber activity is a rare, non-dystrophic myopathy characterized by generalized myokymia and increased muscle tone associated with delayed motor milestones, leg stiffness, spastic gait, hyperreflexia and Babinski sign. Symptoms may be worsened by febrile illness or anesthesia. 